\title{
Multimeter Measuring Tool Application as Alternative Method of Resistance Characteristics Discern Between the Sauce brand "abc" Sauce with brand "dena"
}

\author{
Salisa Nurrohmah", Gebrina Rahmah ${ }^{* *}$, Frida Agung Rakhmadi*** \\ Physics Department, Faculty of Science and Technology, UIN Sunan Kalijaga \\ J1. Marsda Adisucipto No. 1 Yogyakarta 55281, Indonesia \\ E-mail: salisa.nr28@gmail.com*, gebrinarahmah98@gmail.com ${ }^{* *}$, frida.rakhmadi@uin-suka.ac.id ${ }^{* * *}$
}

\begin{abstract}
The sauce is an ingredient in cooking or food complement. The materials used is chili or tomato sauce. Use of the basic ingredients in the sauce affect the physical quantities of the dressing. One of the physical quantities that can be measured is resistance. Resistance can be defined as the amount that inhibits electrical current. The purpose of this study was to determine the resistance characteristics of materials $\mathrm{ABC}$ sauce and dressing materials Dena. Different from the base material, the resistance value will be different sauces. By using Analog Multimeter and perform measurements five times, found a resistance value of $(4.6 ; 4.6 ; 4.8 ; 4.8 ;$ and 4.7) $\Omega$ for ABC dressing material and material obtained resistance value Dena sauce by $(4.3 ; 4.4 ; 4.4 ; 4.3$; and 4.5$) \Omega$ with the volume of each sauce is $\pm 10 \mathrm{ml}$.
\end{abstract}

Keywords: Multimeter, Resistance, Sauce

\section{INTRODUCTION}

The sauce made from pureed fruit is attractive (usually red), have aromas and flavors that stimulate (the same as without the spicy taste). The word "sauce" comes from French language (Sauce) taken from Latin language salsus meaning "salted."

Sauce constitute fluid used when cooking or served together food as a flavoring or flavor enhancer. Therefore, the quality of the sauce should be noted that when consumed not harm the body. Consuming lowquality sauces will result in several diseases such as indigestion, sore throat, disorders of the nervous system, it can even lead to cancer.

The sauce is made from a mixture of tomato puree (tomato pulp thick) with food additives such as sugar, salt, vinegar, spices (pepper, clove, garlic, and cinnamon), maize starch, and preservatives. The nutritional value contained within each brand is different sauces. This is due to the quality of a product sauce ingredients are characteristic of each plant. Therefore, this study aims to determine differences in the quality of the sauce seen from the resistance.

The resistance of a conductor is a prisoner to impede the flow of electric current any material which is used as a conductor has the characteristics of different obstacles. ABC sauce ingredients tend to have a greater obstacle than the sauce ingredients Dena. Which causes Here resistance than larger $\mathrm{ABC}$ sauce ingredients.

\section{MATERIALS AND METHODS}

\section{Tools and Material}

Materials need to be prepared are two different samples of the sauce ingredients. One sample of the sauce ingredients and one sample $\mathrm{ABC}$ Dena sauce ingredients, each of which is mixed with $\pm 10 \mathrm{ml}$ of water.The tools used in data collection is Multimeter Analog, connecting cables, and wires.

\section{Data Collection Methods}

After preparation tools and materials, the next step is data collection. The retrieval of data using sample measurement method using Analog Multimeter. This measurement is performed to measure the resistance of a sample.

Measurements are made by dipping a wire that has been linked with a connecting cable of the multimeter into each sample. Data collection was performed by varying the measurement of five times. Data retrieval is at room temperature $32^{\circ} \mathrm{C}$.

Data analysis was performed after the data from the measurement variation obtained in order to determine the difference in the sample being measured. Data discrepancies are analyzed whether overlap. Which can then be known whether it can be used as a detection system or not.

\section{Data Processing}

The data processing method is to determine the magnitude of the resistance by using the equation.

$$
\mathbf{R}=\frac{\sum R_{n}}{n}
$$

By $\mathrm{Rn}$ is the resistance variation to $\mathrm{n}$ and $\mathrm{n}$ is the number of trials. Having obtained an average magnitude resistance followed by determining a misprint of an experiment that uses an equation 


$$
\Delta \boldsymbol{R} \boldsymbol{n}=|\boldsymbol{R} \boldsymbol{n}-\boldsymbol{R}|
$$

With the data are corrected on the resistance to $n$. Then the average value of the resistance error can be obtained by the equation

$$
\overline{\Delta R \boldsymbol{n}}=\sum \frac{\|R n-R\|}{n}
$$

\section{RESULTS AND DISCUSSION}

\section{Data Processing}

The results of data processing are shown in Table 1.1

Table 1. Results of data processing.

\begin{tabular}{ll}
\hline ABC sauce ingredients $(\boldsymbol{\Omega})$ & Dena sauce ingredients $(\boldsymbol{\Omega})$ \\
\hline 4.6 & 4.3 \\
4.6 & 4.4 \\
4.8 & 4.4 \\
4.8 & 4.3 \\
4.7 & 4.5 \\
\hline
\end{tabular}

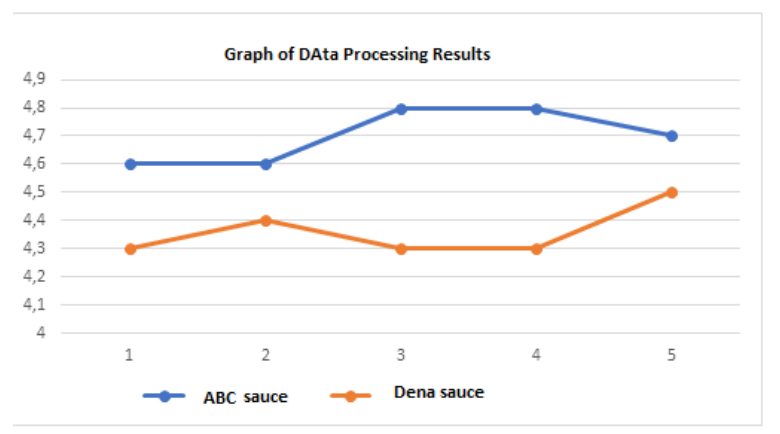

Figure 1. Graph data processing results by.

The average value of resistance obtained from the sum of the data result is then divided by the number of $4,7 \Omega$ data retrieval is to sample the sauce ingredients and $4,4 \Omega \mathrm{ABC}$ to sample the sauce ingredients Dena.
From this research analyzed data results. Where the resistance results from the sauce ingredients $A B C$ is larger than the sauce ingredients Dena. The viscosity of each sauce also shows the differences between the two samples. ABC sauce thicker material, causing the resistance is larger than the sauce ingredients Dena. So we can say that the sauce ingredients $A B C$ is more qualified than the sauce ingredients Dena.

From the graph shows the results of this study samples of the sauce ingredients and sauces $A B C$ Dena materials do not overlap, where the sample sauce $A B C$ material is in the range of 4.7 while dressing material is in the range of 4.4 Dena. The data is distinguished by its resistance. Therefore, these data can be used as raw material in the manufacture of the detection system.

\section{CONCLUSIONS}

From the graph shows the results of this study samples of the sauce ingredients and sauces $\mathrm{ABC}$ Dena materials do not overlap, where the sample sauce $A B C$ material is in the range of 4.7 while dressing material is in the range of 4.4 Dena.

Different from the base material, the resistance value will be different sauces. By using Analog Multimeter and perform measurements five times, found a resistance value of $(4.6 ; 4.6 ; 4.8 ; 4.8$; and 4.7) $\Omega$ for $\mathrm{ABC}$ dressing material and material obtained resistance value Dena sauce by $(4.3 ; 4.4 ; 4.4 ; 4.3$; and 4.5) $\Omega$ with the volume of each sauce is $\pm 10 \mathrm{ml}$. The data is distinguished by its resistance. Therefore, these data can be used as raw material in the manufacture of the detection system.

\section{REFERENCES}

https://id.wikipedia.org/wiki/Saus

https://naomielisinta.wordpress.com/2014/11/07/cara-pembuatan$\underline{\text { saos/ }}$ 